\title{
Research on Reliability and Validity Based on Computer Fractal Theory and Structural Equation
}

\author{
Rongyuan Wang \\ Faculty of Foreign Languages \& Cultures, Kunming University of Science and Technology, \\ Chenggong, China
}

\begin{abstract}
Keywords: standard deviation; validity coefficient; scale; effect model; related fractal; structural equation
\end{abstract}

\begin{abstract}
The teachers' professional identity is the synthesis that includes the teachers' positive cognition, experience, behavioral tendency of the profession and the internalization of professional role. It is a kind of teachers' positive attitude related to the profession. This study analyzes the present situation of research on the professional identity of universities foreign language teachers in China. Then, it uses the quality and quantity method to have system research on the concept, structure, characteristics and influence effects model of the teachers' professional identity. At the same time, the study establishes the measuring tool of teachers' professional identity. And the tools meet the requirements of the psychometrics, which uses the scale of teachers' professional identity to have sample survey. Based on the theory how to construct the concept and structural dimension of teachers' professional identity it uses the correlation analysis, structural equation and other model methods to discusses the influence effects on teachers' professional identity. In this way, it can provide the scientific theory basis to improve the level of foreign language teachers' professional identity.
\end{abstract}

\section{Introduction}

With the improvement of material living standards, people pay more attention to the spiritual pursuit, and now the identity is a spiritual level of people's common pursuit, and the teacher's identity of the profession has also decided the attitude of his working behavior[1-3].It also has a significant impact on teacher's self-perception and professional experience.

At the present stage,the education obtains the universal attention, so the university teachers' professional identity also becomes a widely concerned topic. Only when the teachers are working, they can maintain strong professional identity, in this way, they can obtain a spiritual satisfaction.And at the same time,they can feel the pride and individual value brought by the profession. But the current researches on teachers' professional identity are only limited to the researches of the theory, the objects of researches are relatively narrow[4,5].And the elements of the research are not sufficient. And now it is the era of internationalization and globalization, when all the people are learning the English and taking the way of internationalization, we need to strengthen the English learning and pay attention to the English teaching, so this paper analyzed the universities foreign language teachers' professional identity from the angle of scale, which provides practical significance for the universities English teachers to have professional development and planning.

\section{Overview of the literature and research methods}

In social life,we can see a lot of phenomenon of identity, for example, the cultural identity, national identity, and social identity, the organization's identity and so on[6]. Of course professional identity is not only the methods of the pursuit of living, but also reflects the value of a person and a way of a person's sense of responsibility of the work[7]. Professional identity needs people to carry out a professional activity in a long time, so the characteristics, content and even the social economic value and meaning of the professional activities are generated at the familiar and very recognized conditions, it reflects the identity of this profession and gives a definite evaluation, it has the related links with people's satisfaction of the work and the level of professional burnout and even the professional pressure. 
Teachers' professional identity is not only a process, but also a kind of state. The "process" of the teaching profession reflects the experience and the gradual development of the teachers from the teaching activities, at the same time it also constantly consolidate the status and role of the teachers, and the state reflects the teachers' identity degree of the teaching profession.

This paper mainly designed the questionnaire, and according to the opinions of the experts, the questionnaire had pretest and score.It judged the validity of the questionnaire, and then after the full change and adjustment it carried on the investigation of the universities foreign language teachers to test the current situation of the universities foreign language teachers' professional identity. The methods of testing the reliable characteristic of the questionnaire mainly have the analysis on the validity and reliability.

The reliability is mainly used to test the consistency or stability of the research data. Consistency is the mutual correlation of the problems of the test questionnaire, and this is to avoid the questionnaire from testing the same content. And stability is the reliability coefficient of the unrealistic and repetitive research data that generated from the same person in the situation of using the same questionnaire. Of course if the rationalization degree of the questionnaire is high, the research data will have high relevance, and the reliability test mainly uses $\alpha$ model and the methods of the total item's correlation coefficient and the consistency of internal index. The expression of the reliability coefficient is[8]:

$$
R_{x x}=\frac{S T 2}{S_{x} 2}
$$

ST2: the true variation value; $\mathrm{Sx} 2$ : the actual variation value. They can be calculated by using the SPSS software to input data.

The coefficient expression of $\alpha$ model is[9]: $\alpha=\left(\frac{k}{k-1}\right)\left(1-\frac{\sum S i 2}{S \times 2}\right)$

$\mathrm{K}$ : the total number of questions in the questionnaire; Si2: a question; Sx2: the variance of all the research data of questionnaire. The research data should be processed through the descriptive statistical methods, and they are the average value and standard deviation.

The expression of the research data's average value is[10]: $\bar{x}=\frac{\sum x}{m}$

The expression of the research data's standard deviation is[11]: $s=\sqrt{\frac{\sum(x-\bar{x})^{2}}{m-1}}=\sqrt{\frac{s S}{m-1}}$

\section{Analyses on reliability and validity of university foreign language teachers' professional identity}

The questionnaire indexes of foreign language teachers' professional identity mainly referred to the related literature material, it also had the preliminary investigation according to the opinions of the experts, the problems had the preliminary adjustment and collation, and then the investigation questionnaire was finished to carry out the investigation on the university foreign language teachers[12-14]. The investigation questionnaire mainly took five score system, it used five-point likert scale, the answer of the question were set as "strongly agree " (5 points), "basically agree" (4 points), "general" (3 points), "basically disagree" ( 2 points) and " strongly disagree " (1 point). The universities foreign language teachers' professional identity designed by the questionnaire had four aspects: professional expectations, professional will, professional values and professional behavior and so on. And each dimension index also had different secondary indexes. The situation of the research data in the investigation questionnaire that focused on the foreign language teachers can be seen in Table 1, the effective recovery rate of questionnaire reaches $97.87 \%$.

TABLE I. Questionnaire situation of universities foreign language teachers' professional identity

\begin{tabular}{|c|c|c|c|}
\hline The total number ( a ) & The recovery number( a ) & The effective number( a ) & Effective recovery rate \\
\hline 50 & 47 & 46 & $97.87 \%$ \\
\hline
\end{tabular}


It is through the method of KMO to analyze factors of the original data variable, when the calculated spherical test values of Bartlett are in the level of $p<0.001$, it is a significant level. The value of KMO is equal to 0.811 . The four dimensions index factors designed by questionnaire got rid of the unreasonable problem, and then the remaining problems can get loading matrix of the rotating factor through the oblique rotation, and at the same time the contribution value and common value and cumulative explain rate value of the corresponding problems are shown in Table 2.

TABLE II. The contribution value and common value and cumulative explain rate value of each factor's factor

\begin{tabular}{|l|l|l|l|l|l|}
\hline \multicolumn{1}{|c|}{ Projects } & $\begin{array}{c}\text { Professional } \\
\text { expectations }\end{array}$ & $\begin{array}{c}\text { Professional } \\
\text { will }\end{array}$ & $\begin{array}{c}\text { Professional } \\
\text { values }\end{array}$ & $\begin{array}{c}\text { Professional } \\
\text { behavior }\end{array}$ & $\begin{array}{c}\text { Communalities } \\
\text { value }\end{array}$ \\
\hline $\begin{array}{l}\text { 9. Hope to be able to better teaching and educating } \\
\text { the students }\end{array}$ & 0.938 & & & 0.768 \\
\hline 8. Hope to continue the self-improvement & 0.929 & & & & 0.741 \\
\hline 1. Hope to have more communication with students & 0.860 & & & & 0.637 \\
\hline $\begin{array}{l}\text { 14. Hope to have always been engaged in education } \\
\text { work }\end{array}$ & & 0.976 & & & 0.702 \\
\hline $\begin{array}{l}\text { 2. If there are other opportunities, the work may be } \\
\text { changed. }\end{array}$ & & 0.871 & & 0.764 \\
\hline $\begin{array}{l}\text { 4. The education work is respected by the people. } \\
\text { 10. Teachers' social status will be relatively high }\end{array}$ & & & -0.931 & & 0.517 \\
\hline $\begin{array}{l}\text { 3. Hope to become the role model of student } \\
\text { learning }\end{array}$ & & & -0.906 & & 0.747 \\
\hline $\begin{array}{l}\text { 7. Hope to keep self-enrichment } \\
\text { 11. Hope to become a good teacher }\end{array}$ & & & & -0.912 & 0.791 \\
\hline Characteristic values & 2.893 & 2.413 & 2.730 & -0.761 & 0.763 \\
\hline The contribution value & 41.926 & 24.630 & 20.685 & -0.743 & 0.741 \\
\hline Cumulative contribution rate value & 41.926 & 66.556 & 87.241 & 9.717 & \\
\hline
\end{tabular}

From Table 2 and Figure 1,we can see that in addition to the problems of professional values and professional behavior are negative, the professional expectations and professional will are positive, the minimum value is 0.871 , it says that if there are other opportunities, they may change the work; the first is the hope of having always been engaged in education work, the value is 0.976; and the second is the hope of better imparting knowledge and educating the students, the value is 0.938 . The communalities are basically consistent, in addition to the teacher's job can be respected, its value is 0.517 , and the hope of having more communication with students, its value is 0.637 , but the rest are more than 0.7 . The value of contribution rate of professional expectations in these four factors is the largest, it is 41.926; the second is the professional will, its value is 24.630; the last is professional behavior, its value is 9.245 , and the characteristics values of four factors also are in the range from 2.413 to 2.893 , the value of cumulative contribution reaches 96.486 . So this can well reflect the current situation of university foreign language teachers' professional identity.

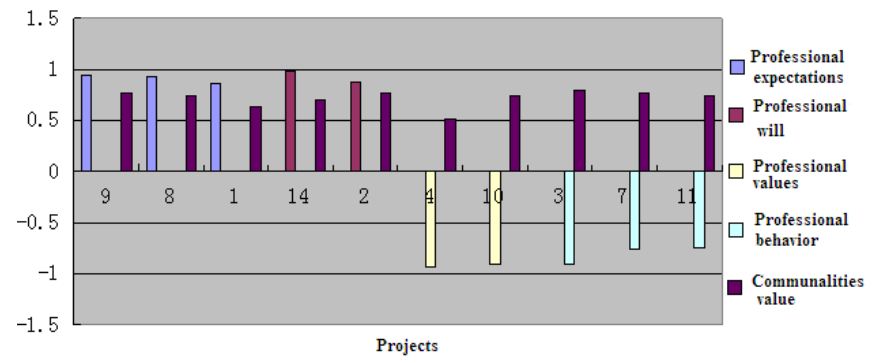

Figure 1. The contribution value and common value and cumulative explain rate value of each factor's project TABLE III. Analysis on the reliability coefficient of universities foreign language teachers' professional identity

\begin{tabular}{|c|c|c|}
\hline Factor index & Split-half reliability values & The $\boldsymbol{\alpha}$ Model coefficients \\
\hline Professional expectations & 0.82 & 0.86 \\
\hline Professional will & 0.92 & 0.98 \\
\hline Professional values & 0.83 & 0.83 \\
\hline Professional behavior & 0.69 & 0.72 \\
\hline Total questionnaire & 0.92 & 0.99 \\
\hline
\end{tabular}

From the reliability coefficient of the universities foreign language teachers' professional identity in the Table 3 and Figure 2, we can know that minimum value of the split-half reliability of factor index of the professional behavior is 0.69 , the biggest aspect is the professional will, its value is 0.92 , 
the following aspect is the professional values, its value is 0.83 , and the reliability coefficient is more than 0.72 , the biggest aspect is professional will, its value is 0.98 , the following is the professional expectations, its reliability coefficient is 0.86 . And the split-half reliability of the total questionnaire also reaches 0.92 , the maximum value of reliability coefficient is 0.99 , this fully illustrates that the test reliability of the questionnaire based on the scale is very good, and it also shows that the design of questionnaire is reasonable and effective.

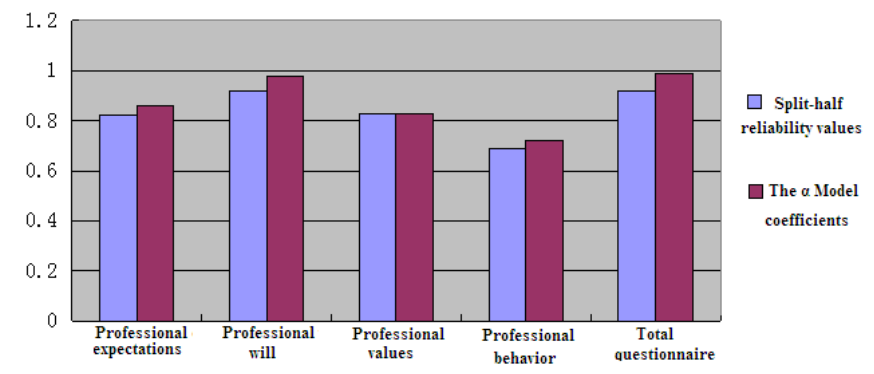

Figure 2. The contrast figure of reliability coefficient of the universities foreign language teachers' professional identity

From the Table 4, the correlation coefficient of each factor of the universities foreign language teachers' professional identity is in the range between 0.217 and 0.625 , correlation is the moderately low status, and it also shows the relative independence between the each factor, it also reflects that the structure validity of the questionnaire is good.

TABLE IV. Analysis on the validity of each factor of the universities foreign language teachers' professional identity

\begin{tabular}{|c|c|c|c|c|}
\hline & Professional expectations & Professional will & Professional values & Professional behavior \\
\hline Professional expectations & 1 & & & \\
\hline Professional will & 0.217 & 1 & & \\
\hline Professional values & 0.372 & 0.431 & 1 & \\
\hline Professional behavior & 0.625 & 0.314 & 0.451 & 1 \\
\hline
\end{tabular}

From the Table 4 and Figure 3, we can see that there has certain correlation between the factors, and the related degree is different, and when the questionnaire topic is in the level of $p<0.001$, the correlation degree is in the range between 0.663 and 0.896 , this shows very good statistical significance. There has correlation between the professional expectations and professional will, professional will and professional values, professional values and professional behavior, professional expectations and professional behavior and so on, this shows that the questionnaire factor can feedback the content of the university foreign language teachers' professional identity in the scale.

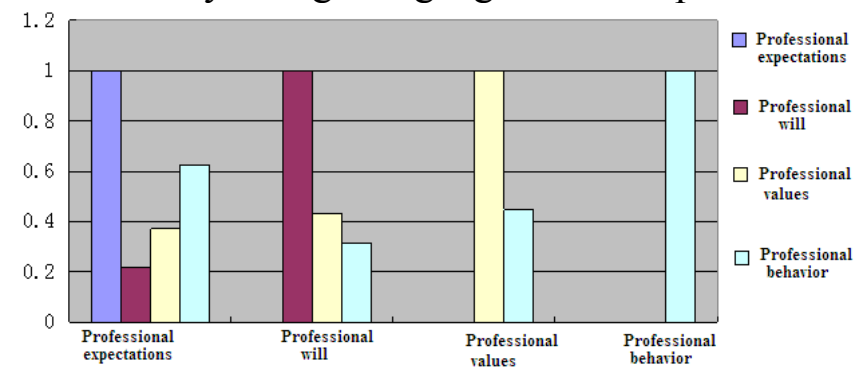

Figure 3. The analysis figure of each factor's validity of the universities foreign language teachers' professional identity

\section{Conclusion}

In the era of internationalization and globalization, we need to strengthen the English learning and pay attention to the English teaching.And the teachers' professional identity obtains general attention.From the angle of scale, this paper analyzed the universities foreign language teachers' professional identity, which had the score through the questionnaires and by using the analysis of validity and reliability to verify the validity of the questionnaires. Then, this paper constructed the structure of the professional expectations, professional will, professional values and professional behaviors, which is an effective tool to have the feedback of the universities foreign language teachers' professional identity. And it can guide the university to strengthen the foreign language teachers' professional identities in this way. Teachers' professional identity is not only the 
significance and educational value of the teachers in their teaching career, but also the inner satisfaction and the sense of pride of the teachers. It is the recognition and affirmation of the selfworth, and at the same time the teachers can feel happy in the education profession.

\section{References}

[1] Song Guangwen,Wei Shuhua. Analysis on the related factors that have influence on the teachers' professional identity .Psychological development and education,2009 (01):58-61

[2] Bo Yanling. Research on high teachers and students teachers' professional identity .Journal of Guangxi normal university,2010(9):09-12

[3] Cheng Chunxia. Research on burnout defense mechanism of university English teachers' profession .Journal of Chifeng institute (Chinese philosophy and social science edition),2012(02):30-33

[4] Zhang Jie. Research on Henan normal college PE teachers' profesion burnout .Sports journal,2009 (02):72-75

[5] Wang Jinglan. Research on Lanzhou preschool teachers' professional identity and professional development .Journal of Northwest normal university,2010(3):11-13.

[6] Wei Shuhua, Shan Xianguang. The current research situation of foreign teachers' professional identity .Foreign education research, 2012(3):67-69

[7] Shi Xiaobo. Research on narrative case of male preschool teachers' professional identity .Southwest university.2009.

[8] Ji Qingfen. Research on the college English teachers' profession burnout .Journal of Hubei three gorges professional technology institute,2011(02):89-92

[9] Liao Jianmei. Study of the current situation of ordinary university PE teachers' role cognition .Journal of Harbin sports institute,2010 (03):45-48

[10] Wang Fang. Research of private college English teachers' profession burnout .Journal of Zhangjiakou vocational technology college,2012 (02):23-25

[11] Kang Xiaoxia. Analysis on the development characteristics and influence factors of early childhood teachers' professional commitment .East China normal university.2009.

[12] Shen Jiliang, Li Yongxin, Zhang Na. Study of graphical method of teachers' organizational identification measurement .Psychological research,2011(01):77-80

[13] Jiang Xiaohong. Analysis on connotation and strategy of teachers' professional identity .Global education outlook,2009 (02):31-33

[14] Shi Junqi, Wang Lei. Validity test of general self-efficacy scale . Journal of Chinese mental health,2012 (03):62-65. 